\title{
Preliminary evidence of the validity process of the Autism Diagnostic Observation Schedule (ADOS): translation, cross- cultural adaptation and semantic equivalence of the Brazilian Portuguese version
}

\author{
Evidências preliminares do processo de validação da Autism Diagnostic \\ Observation Schedule (ADOS): tradução, adaptação transcultural e \\ equivalência semântica para a versão em português do Brasil
}

Maria Clara Pacífico, ${ }^{1}$ Cristiane Silvestre de Paula, ${ }^{2,3}$ Victor Santos Namur ${ }^{2}$ Rosane Lowenthal, ${ }^{4,5}$ Cleonice Alves Bosa, ${ }^{6}$ Maria Cristina Triguero Veloz Teixeira ${ }^{2}$ (D)

\begin{abstract}
Objectives: To translate and back-translate the Autism Diagnostic Observation Schedule (ADOS) into Brazilian Portuguese, to assess its cross-cultural semantic equivalence, and to verify indicators of quality of the final version by analyzing the interrater reliability of the ADOS scores.

Methods: This study had three stages: 1) translation and backtranslation; 2) semantic equivalence analysis; and 3) pre-test to verify the agreement between mental health specialists and an ADOS senior examiner regarding the scoring procedure. Authorization to translate and carry out the cultural adaptation of the instrument was first obtained from the Western Psychological Services, publishers of the instrument.

Results: The main preliminary results pointed to good equivalence between the original English version and the final version and the Brazilian version following the cultural adaptation process. Some semantic differences were found between the original version and the back-translation into English, but they did not interfere with the first translation into Portuguese or into the final version. One of the limitations of the study was the small sample size; for that reason, the inter-rater reliability of the ADOS scores between the specialists and the senior examiner using the kappa coefficient was adequate for 7 out of 10 areas.

Conclusions: We conclude that the creation of an official Brazilian version of ADOS will help to strengthen clinical and scientific research into ASD, and deter the use of other unauthorized versions of ADOS in the country.

Keywords: Autism spectrum disorder, Autism Diagnostic Observation Schedule, translation, cultural adaptation.
\end{abstract}

Resumo

Objetivos: Traduzir e retrotraduzir a Autism Diagnostic Observation Schedule (ADOS) para a língua portuguesa do Brasil, verificar sua equivalência semântica transcultural e verificar indicadores de qualidade da versão final analisando a confiabilidade interavaliadores na pontuação da ADOS.

Métodos: O estudo teve três etapas: 1) tradução e retrotradução; 2) análise de equivalência semântica; e 3) pré-teste para verificar a concordância entre especialistas em saúde mental e um examinador sênior em relação ao procedimento de pontuação. A realização do estudo foi feita com a autorização da Western Psychological Services, distribuidor oficial do instrumento.

Resultados: Os principais resultados preliminares indicaram uma boa equivalência entre a versão original em inglês e a versão brasileira após o processo de adaptação cultural. Algumas diferenças semânticas foram encontradas entre a versão original e a retrotradução, mas que não interferiram na primeira tradução para o português nem na versão final. Uma das limitações do estudo foi o tamanho amostral pequeno; em razão disso, a confiabilidade interavaliadores entre as pontuações da ADOS dadas pelos especialistas e pelo examinador sênior utilizando o coeficiente kappa foi adequada para 7 das 10 áreas.

Conclusão: Conclui-se que, com a versão brasileira da ADOS, oficializa-se uma versão única da escala em português, fortalecendo os campos clínicos e científicos de pesquisa em TEA e impedindo que no país sejam utilizadas outras versões não autorizadas da ADOS.

Descritores: Transtorno do espectro autista, Autism Diagnostic Observation Schedule, tradução, adaptação cultural.

\footnotetext{
${ }_{1}$ Programa de Transtornos do Espectro do Autismo (PROTEA), Programa de TEA, Ambulatório, Hospital das Clínicas, Faculdade de Medicina, Universidade de São Paulo (USP), São Paulo, SP, Brazil. ${ }^{2}$ Programa de Pós-Graduação em Distúrbios do Desenvolvimento, Universidade Presbiteriana Mackenzie, São Paulo, SP Brazil. ${ }^{3}$ Departamento de Psiquiatria, Universidade Federal de São Paulo (UNIFESP), São Paulo, SP, Brazil. ${ }^{4}$ Programa de Pós-Graduação de Ciências da Saúde, Departamento de Saúde Mental, Faculdade de Ciências Médicas da Santa Casa de São Paulo, São Paulo, SP, Brazil. ${ }^{5}$ Programa de Pós-Graduação em Saúde da Comunicação Humana, Departamento de Saúde Mental, Faculdade de Ciências Médicas da Santa Casa de São Paulo, São Paulo, SP, Brazil. ${ }^{6}$ Programa de PósGraduação em Psicologia, Universidade Federal do Rio Grande do Sul (UFRGS), Porto Alegre, RS, Brazil.

Submitted Jul 24 2018, accepted for publication Dec 102018.

Suggested citation: Pacífico MC, de Paula CS, Namur VS, Lowenthal R, Bosa CA, Teixeira MCTV. Preliminary evidence of the validity process of the Autism Diagnostic Observation Schedule (ADOS): translation, cross-cultural adaptation and semantic equivalence of the Brazilian Portuguese version. Trends Psychiatry Psychother. 2019;41(3):218-226. http://dx.doi.org/10.1590/2237-6089-2018-0063
} 


\section{Introduction}

The diagnosis of autistic spectrum disorder (ASD) requires a careful evaluation of different abilities related to verbal and non-verbal communication, language, social interaction, social cognition and behavior patterns. ${ }^{1}$ ASD is one of the most severe disorders of child development due to its impact on adaptive functioning in all areas of daily living. According to recent studies, the estimated prevalence of ASD is between $0.6 \%$ and $1 \%{ }^{2-}$ 4 A diagnostic evaluation of ASD, as with other neurodevelopmental disorders, requires the specialist to have accurate knowledge of both expected child developmental milestones and signs and symptoms of ASD and other neurodevelopmental conditions and neurological diseases, which are often comorbid with ASD. ${ }^{5}$ The use of specific instruments to guide clinical judgment - either screening for indicators of the disorder or to aid in diagnosis - is essential. Such instruments may be formatted as observation scales administered to the child, or in the format of questionnaires and interviews used with caregivers. ${ }^{6,7}$ In Brazil, the following instruments with adequate psychometric properties are available for the screening of signals indicative of ASD: 1) Autism Behavior Checklist $(A B C)^{8,9}$; 2) Autism Screening Questionnaire (ASQ) ${ }^{10,11} ; 3$ ) Childhood Autism Rating Scale (CARS) ${ }^{12,13}$; and 4) Modified Checklist for Autism in Toddlers (M-CHAT). ${ }^{14}$ The M-CHAT was only translated into Portuguese, with no verification of its psychometric properties. ${ }^{15}$

In the last five years, other screening instruments based on direct observation of the child have been developed and/or tested in Brazil. These are: Protocolo de Avaliação Comportamental para Crianças com Suspeita de Transtorno do Espectro Autista - Versão Revisada (PROTEA-R; in English: Behavioral Assessment Protocol for Children Referred for a Possible Autism Spectrum Disorder - Revised Version) ${ }^{16}$; Protocolo de Observação Estruturada para Rastreamento do Autismo (OERA; in English: Structured Observation for Autism Screening17,18; and the Autism Mental Status Exam (AMSE), an observational scale for recording signs and symptoms of ASD. ${ }^{19-21}$

The PROTEA-R is indicated for preschool nonverbal children between 18 and 48 months of age; it is a direct observation instrument conducted in play settings. It is geared toward identification of behaviors characteristic of the disorder, such as social/communication impairment and repetitive and stereotyped behaviors. It also identifies the potential for the child's development, making it possible to develop a descriptive profile for the therapeutic plan. ${ }^{16}$
The OERA, in turn, is an observational autism screening instrument based on the Autism Diagnostic Observation Schedule (ADOS). It is quick, consistent and inexpensive, and comprises a set of tests that allow the evaluation of visual contact indicators, shared attention, socio-emotional reciprocity, imagination and communication. A recent validation study of the OERA was conducted in a sample of 99 children aged 3 to 10 years, and its results showed excellent fit indices in the confirmatory factor analysis. From a cut-off of five or more points, OERA showed excellent sensitivity (92.75) and specificity (90.91). ${ }^{18}$ In that recent study, the assessment of its psychometric properties showed adequate results for sensitivity (0.91) and specificity (0.98), as well as high correlation with CARS $(\rho=0.91, p<0.01) .{ }^{18}$

Finally, the psychometric properties of the validity study of the AMSE, involving 260 Brazilian children and adolescents with ASD, showed good internal consistency $(0.74)$, sensitivity $(0.91)$, and specificity $(0.98)$, in addition to high correlation with the CARS-BR $(\rho=0.91$, $\mathrm{p}<0.01)^{21}$

Although there are several instruments in Brazil with adequate psychometric properties suitable for screening for ASD signs, ${ }^{6}$ there is still a shortage of instruments with diagnostic purposes that can contribute to the establishment of ASD prevalence rates in the country. Currently, two gold-standard instruments are recognized: $\mathrm{ADOS}^{22-24}$ and the Autism Diagnostic Interview (ADI). ${ }^{25,26}$ Both instruments have been translated and evaluated for their psychometric properties in other languages. ${ }^{27-36}$ The revised version of the ADI was translated and adapted to Brazilian Portuguese and tested for psychometric properties of discriminant validity. ${ }^{33}$ However, no previous study has been published on the translation, cultural adaptation or verification of the psychometric properties of ADOS in Brazilian Portuguese.

ADOS was developed by Lord et al. in $1989^{22}$ and is a semi-structured standardized protocol for the observation and evaluation of social and communication behaviors in children and adults with suspected ASD. The ADOS was originally developed to evaluate children who had verbal fluency. Later, the Pre-Linguistic Autism Diagnostic Observation Schedule (PL-ADOS) $^{23}$ was designed for pre-school children with little or no expressive language. The objective was to allow spontaneous behavior in a standardized context. Its latest version, ADOS-2, was developed to improve the accuracy of the original ADOS diagnostic algorithms. Published by the Western Psychological Services (WPS), the second edition of ADOS, ${ }^{23}$ as in the original version, evaluates the domains of communication, social interaction, play/imagination 
and restricted and repetitive behaviors. However, data from the ADOS preliminary validation process described in the present article derived from the first version, taking into account that, in Brazil, the official WPS certification only exists for that previous version. ADOS has good psychometric qualities, with a high level of reliability, internal consistency and validity confirmed by studies conducted in different countries. ${ }^{31,32,34,35,37-40}$ Currently, ADOS has official translations in 20 languages, but has only been published in 15 countries in their respective local language, while the others remain in press. ${ }^{41}$

ADOS contains four modules that vary according to the level of expressive language of the child. Each module consists of specific structured tasks that are designed to support the observation and evaluation of manifestations compatible with ASD in the areas of communication, social interaction and behavior patterns. The activities performed and the subsequent scores differ in each module. The modules of the first version of ADOS are as follows:

- Module 1, pre-verbal/single words, intended for non-verbal children or who can use single words from 31 months of age and comprises 5 areas with 29 items.

- Module 2, phrase speech, intended for children with verbal fluency, with 5 areas and 28 items.

- Module 3, fluent speech (child/adolescent), intended for children and adolescents who have verbal fluency, comprising 5 areas and 28 items.

- Module 4, fluent speech (adolescent/adult), intended for adolescents and adults with verbal fluency and comprising a total of 5 areas and 31 items.

The ADOS score scale ranges from 0 to 3: a score of 0 indicates no evidence of abnormal behavior; 1 indicates presence of slightly unusual behaviors or abilities; 2 indicates abnormal behaviors or abilities; and 3 indicates the expressive presence of abnormal behaviors. There are other scores: 4, when no word or word approximation is found at the language level of module $1 ; 7$, in the presence of an excess of a particular ability or behavior that makes it impossible to evaluate the item; 8, when there is an insufficient amount of a particular ability or behavior to make an evaluation of the item.

The WPS owns the commercial copyright of ADOS..$^{42}$ In Brazil, currently there is not an authorized distributor of the instrument. Use must be pre-authorized in writing by the WPS. Mental health professionals interested in administering ADOS, whether for research or clinical purposes, must obtain certification from the WPS or centers authorized by the WPS to use the instrument.

The objectives of this study were to translate and back-translate the ADOS into Brazilian Portuguese, to assess its cross-cultural semantic equivalence and to verify indicators of quality of the final version by analyzing the inter-rater reliability of the ADOS scores.

\section{Methods}

This study comprised three stages: 1) translation and back-translation; 2) semantic equivalence analysis; and 3) pre-test - all of which will be described next. Authorization to translate and carry out the cultural adaptation of the instrument was first obtained from the WPS, publishers of the original instrument. The company required that one of the researchers responsible for the translation be officially registered to apply ADOS. In this case, the first author (MCP) was certified by the Antonia Ayala International Center as an ADOS and ADI trainer. The validity process of the instrument followed the International Test Commission (ITC) guidelines. ${ }^{43}$

\section{First stage: translation and back-translation.}

After receiving approval, the translation process of the instrument began. Following its back-translation to English, a semantic cross-cultural equivalence analysis of the items for use in Brazilian Portuguese was conducted. Figure 1 shows a summary of the translation/adaptation process with respect to the appropriate semantic and cultural adaptations made to the instrument. Each stage of the process will be presented in the results section.

\section{Second stage: semantic equivalence analysis}

The evaluation of semantic equivalence was based on a comparison of the terms and expressions of the original version with the back-translated version for each of the questions, taking into account cross-cultural equivalence for use in Brazilian Portuguese. It was based on Reichenheim \& Moraes's ${ }^{44}$ guidelines. For this purpose, we first verified if the understanding of the professional that would apply the ADOS was similar in both cultures. The quality of the translation according to the referential meanings of the words and phrases was used for the analysis of denotative equivalence. The quality of the translation based on the referential sense of words and phrases served for the analysis of connotative equivalence.

A complementary analysis to the semantic equivalence was conducted with a construct validity analysis based on objectivity and clarity criteria. 
Three bilingual judges (two psychologists and one speech therapist) specialized in neurodevelopmental disorders, specifically ASD, assessed modules 1 and 3 of the Brazilian Portuguese version. All translated items of modules 1 and 3 , and the observation protocol of these modules, were evaluated by the judges according Pasquali's ${ }^{45}$ criteria of objectivity and clarity. Objectivity was evaluated by checking whether the translation of the item was adequately described for its correct application and scoring. Clarity was evaluated by checking whether the translation of the item was clear and intelligible for its application and scoring by professionals in the area. Each item was scored on this scale from 0 to 2 . Mean scores obtained in each criterion were calculated according to the areas of modules 1 and 3 .

\section{Third stage: pre-test}

The objective of the pre-test stage was to verify the agreement between mental health specialists and an ADOS senior examiner regarding the scoring procedure. The senior examiner was MCP (first author), certified for ADOS application by the Antonia Ayala International Center. The inclusion criterion for mental health specialists was to have an employment contract at a specific reference unit specialized in the care of children and adolescents with ASD in the state of São Paulo, namely, the Centro de Atenção Integrada à Saúde Mental, Irmandade da Santa Casa de Misericórdia de São Paulo. All specialists were experienced in ASD diagnostic evaluation (one psychologist, two speech therapists, one occupational therapist, and one nurse). Five specialists administered ADOS module 1 (to five patients), and four among those five administered ADOS module 3 (to four patients). The sample for the verification of agreement indices was composed of nine children aged between 4 and 13 years (nine males).

The five specialists were trained in the use of the ADOS by the 1 st author of the article (MCP). The 16-hour-training program occurred at the Centro de Atenção Integrada à Saúde Mental, Irmandade da Santa Casa de Misericórdia de São Paulo. Training covered both theory and administration/scoring of module 1 and 3 items. Two videos were used, showing the administration of both modules 1 and 3 , and independent scorings were conducted by the five specialists. These scorings were recorded by the senior examiner to evaluate the scoring agreement between each specialist and senior examiner's own

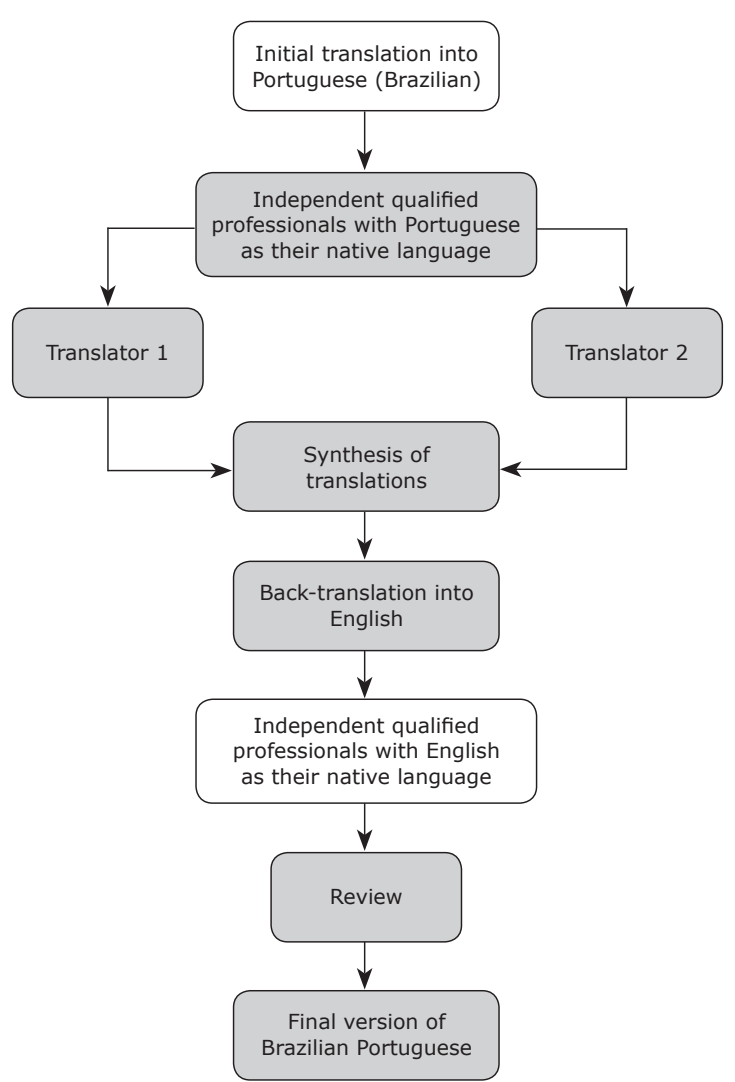

Figure 1 - Translation and back-translation process of the Autism Diagnostic Observation Schedule (ADOS) 
scores. The videos used in training belonged to MCP, and originated from the author's ADOS certification process. Mean agreement was 0.61 for module 1 and 0.63 for module 3 . These values were good according to Siegel \& Castellan, ${ }^{46}$ considering that agreement indices are excellent when values are greater than 0.75 , good between 0.59 and 0.74 , regular between 0.40 and 0.58 , and poor when below 0.40 .

After the training, the specialists administered ADOS module 1 to five patients and ADOS module 3 to four patients, at a total of nine children with suspected ASD. The data were used to compare the scores independently given to the items by the specialists, with the recoding of those scores by the senior examiner. The kappa concordance index $(\mathrm{CI})^{46}$ was used to analyze the concordance between the specialists' and the senior examiner's own scores, and a p-value of 0.05 was adopted for the statistical analyses. ${ }^{47}$ The human research ethics committee of Universidade Presbiteriana Mackenzie approved the study protocol (CAAE 36991614.0.0000.0084).

\section{Results}

First stage: translation and back-translation.

The first translation was performed by two psychologists experienced in ASD. Both had Portuguese as their first language and were fluent in English. Then, the back-translation was performed by a translator fluent in Portuguese with English as their mother tongue.

\section{Second stage: semantic equivalence analysis}

The evaluation of semantic equivalence was denotative and connotative, based on a comparison of terms and expressions between the original version and the back-translated version for each of the questions, respecting cross-cultural equivalence for use in Brazilian Portuguese. No modifications were made where the two versions were equal or where there were different words or phrases that however did not compromise the item to be evaluated. In cases in which there were changes in the meaning between the back-translated version and the original version, changes were made to maintain the original meaning.

After comparing the original and back-translated versions of ADOS, the expressions and words that generated difficulties of understanding were identified and are presented in Table 1 . Not all words, terms or expressions were replaced or adequate for Brazilian Portuguese. Table 1 shows the main highlights of the modifications in the back-translation stage, their respective final translations and the modification category of each one. The final versions were produced by evaluating the semantic equivalence of the words, terms or expressions selected.

Table 1 - Comparison of ADOS terms between original versions, back-translation and cross- cultural adaptation

\begin{tabular}{|c|c|c|c|c|c|}
\hline $\begin{array}{l}\text { ADOS original } \\
\text { (English) }\end{array}$ & Translation & $\begin{array}{l}\text { Back-translation } \\
\text { (English) }\end{array}$ & $\begin{array}{l}\text { Final version with cross- } \\
\text { cultural adaptation to } \\
\text { Brazilian Portuguese }\end{array}$ & Module & $\begin{array}{c}\text { Type of } \\
\text { modification }\end{array}$ \\
\hline Child's affect & Afeto da criança & Child' affection & Afeto da criança & 1,2 & $\mathrm{U}$ \\
\hline $\begin{array}{l}\text { The social directedness } \\
\text { of the child's behaviors }\end{array}$ & $\begin{array}{l}\text { Direcionamento social } \\
\text { do comportamento da } \\
\text { criança }\end{array}$ & $\begin{array}{l}\text { the child's behavior is } \\
\text { socially directed }\end{array}$ & $\begin{array}{l}\text { Direcionamento do } \\
\text { comportamento social da } \\
\text { criança }\end{array}$ & 1 & PM \\
\hline Uses Gaze & Usa o Olhar & Uses his/her regard & Usa o Olhar & $1,2,3$ & $U$ \\
\hline $\begin{array}{l}\text { Pointing with index } \\
\text { finger }\end{array}$ & $\begin{array}{l}\text { Apontar com o dedo } \\
\text { indicador }\end{array}$ & Indicate with indicator & Apontar com o indicador & 1 & PM \\
\hline $\begin{array}{l}\text { Idiosyncratic/odd } \\
\text { words/phrases with } \\
\text { some other language }\end{array}$ & $\begin{array}{l}\text { Palavras estranhas/ } \\
\text { frases com outro tipo de } \\
\text { linguagem }\end{array}$ & $\begin{array}{l}\text { Strange words/phrases } \\
\text { with another type of } \\
\text { speech }\end{array}$ & $\begin{array}{l}\text { Palavras estranhas/ } \\
\text { frases com outro tipo de } \\
\text { linguagem }\end{array}$ & 1,2 & $\mathrm{U}$ \\
\hline $\begin{array}{l}\text { Playful verbal } \\
\text { interaction with the } \\
\text { examinator }\end{array}$ & $\begin{array}{l}\text { Interação verbal com o } \\
\text { examinador durante a } \\
\text { brincadeira }\end{array}$ & $\begin{array}{l}\text { verbal interaction when } \\
\text { playing }\end{array}$ & $\begin{array}{l}\text { Interação verbal em } \\
\text { moldes de brincadeira com } \\
\text { o examinador }\end{array}$ & 1 & PM \\
\hline Eye contact & Contato visual & Visual contact & Contato visual & 1,2 & U \\
\hline Preoccupations & preocupações & Concerns & Preocupações & 4 & $U$ \\
\hline$[\ldots]$ orienting to & {$[\ldots]$ se orientar para } & $\begin{array}{l}\text { Orienting towards/ } \\
\text { turning to }\end{array}$ & [...] se orientar para & 1,2 & $U$ \\
\hline $\begin{array}{l}\text { No approximation of } \\
\text { spontaneous initiation }\end{array}$ & $\begin{array}{l}\text { Nenhuma aproximação } \\
\text { de iniciação espontânea }\end{array}$ & $\begin{array}{l}\text { No spontaneous } \\
\text { approach to initiating }\end{array}$ & $\begin{array}{l}\text { Nenhuma aproximação de } \\
\text { iniciação espontânea }\end{array}$ & 1 & $U$ \\
\hline Hair twisting & Enrolar os cabelos & Rolling the head & Enrolar os cabelos & $1,2,3,4$ & $\mathrm{U}$ \\
\hline Disruption & Falta de controle & Lack of control & Descontrole & $1,2,3,4$ & PM \\
\hline Tantrums & Birra & Stubbornness & Birra & $1,2,3,4$ & $\mathrm{U}$ \\
\hline
\end{tabular}

ADOS = Autism Diagnostic Observation Schedule; $\mathrm{U}=$ unchanged; PM = partially modified. 
In general, there was good equivalence between the terms of the original English version and the terms obtained in the back-translation, as well as between the Portuguese terms in the first translation and in the final version. Some semantic differences (denotative and connotative) were found between the original English version and the back-translation, but they did not interfere with the first translation into Portuguese or with its final version. These items were classified as unchanged in their Portuguese version. These were: "Child's affect," which, despite being back-translated as "Child's affection," suggesting that the test should evaluate in particular expressions of positive affects, remained in Portuguese as "Afeto da criança," indicating that the examiner should evaluate the affective disposition of the child, whether positive or negative. Other terms with the same characteristic were: "gaze," translated as "olhar"; "Eye contact," translated as "contato visual"; "Orienting to," translated as "orientar para"; "Hair twisting," translated as "enrolar os cabelos"; "Idiosyncratic/odd words/phrases with some other language," translated as "Palavras estranhas/ frases com outro tipo de linguagem"; and "tantrums," translated as "birras."

The terms in which modifications made between the first translation into Portuguese and the final version were minimal were considered partially modified. Many of these partial modifications occurred due to a morphological aspect (denotative equivalence) of the phrase. For example, in the term "Pointing with index finger," which was originally translated as "Apontar com o dedo indicador," in the final version was changed to "Apontar com o indicador," since the word finger would be redundant in the sentence. Other changes occurred due to structural problems of the sentence, for example in "The social directedness of the child's behaviors," which was originally translated as "O Direcionamento social do comportamento da criança." Although the first translation is only slightly different from the final translated version, the modification causes a complete change of meaning. In the first translation, the term "direcionamento" is the subject of the phrase, and "social" is used as an adjective, which is incorrect, since the "direction" is not "social." In this case, by connotative criteria, the examiner's attention should be on the child's social behavior. It is known that one of the deficits in ASD is related to sociability, so the final translation corrects the focus of the observation, with "Direcionamento do comportamento social da criança."

The final version of ADOS in Brazilian Portuguese, produced after these procedures, was approved by the WPS (ADOS Copyright (c) 1999, 2001) and by the authorized authors of this article (MCP, CSP), under license of the WPS (625 Alaska Avenue, Torrance, California 90503, USA, rights@wpspublish.com). It was agreed that no additional partial or complete reproduction could be made without the prior written consent of the WPS, with all rights reserved, until an official distributor of the instrument is determined in Brazil. As a result, ADOS in Brazilian Portuguese is available upon request from the WPS trough payment of copyright.

According to Table 2, the results of the construct validity process of the translated items based on objectivity and clarity criteria were adequate. The means of agreement among judges in all areas of modules 1 and 3 ranged from 1.75 to 2 .

\section{Third stage: pre-test}

The results of the agreement analysis between the scores assigned by the senior examiner and those given

Table 2 - Results of construct validity (clarity and objectivity) of modules 1 and 3 of the Brazilian Portuguese version of the Autism Diagnostic Observation Schedule (ADOS)

\begin{tabular}{lcc}
\hline Areas & Mean clarity scores & Mean objectivity scores \\
\hline Observation protocol of module 1 & 1.97 & 2.0 \\
A - Language and communication & 1.75 & 1.83 \\
B - Reciprocal social interaction & 1.94 & 2.0 \\
C - Play & 1.83 & 2.0 \\
D - Stereotyped behaviors and restricted interests & 1.92 & 2.0 \\
E - Other abnormal behaviors & 2.0 & 2.0 \\
& & \\
Observation protocol of module 3 & 1.90 & 2.0 \\
A - Language and communication & 1.89 & 1.96 \\
B - Reciprocal social interaction & 1.87 & 2.0 \\
C - Imagination & 2.0 & 2.0 \\
D - Stereotyped behaviors and restricted interests & 1.92 & 2.0 \\
E - Other abnormal behaviors & 2.0 & 2.0 \\
\hline
\end{tabular}


Table 3 - Agreement (according to kappa coefficient) between the specialists and the senior examiner during the administration of modules 1 and 3 of the Autism Diagnostic Observation Schedule (ADOS)

\begin{tabular}{|c|c|c|c|c|}
\hline \multirow[b]{2}{*}{ Areas } & \multicolumn{4}{|c|}{ Concordance } \\
\hline & No. items per area & $\%$ & Kappa CI & $\mathbf{p}$ \\
\hline \multicolumn{5}{|l|}{ Module 1} \\
\hline Language and communication & 40 & 20 & 0.56 & $0.00 *$ \\
\hline Reciprocal social interaction & 60 & 96.6 & 0.65 & $0.00 *$ \\
\hline Play & 10 & 100 & - & - \\
\hline Stereotyped behaviors and restricted interests & 20 & 95 & 0.89 & $0.00 *$ \\
\hline Other abnormal behaviors & 15 & 93.3 & 0.84 & $0.00 *$ \\
\hline \multicolumn{5}{|l|}{ Module 3} \\
\hline Language and communication & 36 & 80.55 & 0.54 & $0.00 *$ \\
\hline Reciprocal social interaction & 40 & 75 & 0.13 & 0.08 \\
\hline Play & 1 & 100 & - & - \\
\hline Stereotyped behaviors and restricted interests & 20 & 100 & - & - \\
\hline Other abnormal behaviors & 12 & 50 & 0.46 & $0.00 *$ \\
\hline
\end{tabular}

$\mathrm{CI}=$ concordance index.

$* \mathrm{p} \leq 0.05$.

by each specialist while administering module 1 to five children and module 3 to four children are shown in Table 3.

The kappa coefficients were considered good ${ }^{47}$ (language and communication area in modules 1 and 3, kappa $\mathrm{CI}=0.56$ and 0.54 , respectively; reciprocal social interaction and other abnormal behaviors in module 3, kappa CI of 0.54 and 0.46 , respectively). In the areas of stereotyped behaviors and restricted interests and other abnormal behaviors in module 1 , the coefficients were excellent ${ }^{47}$ (kappa CI $=0.89$ and 0.84 , respectively). The kappa coefficient for reciprocal social interaction (module 3) was 75\%, without statistical significance.

\section{Discussion}

The results here described pointed to good equivalence between the original English version and the final version and the Brazilian version following the cultural adaptation process. Some semantic differences were found between the original version and the back-translation into English, but they did not interfere with the first translation into Portuguese or with the final version.

The results of the construct validity process of the translated items in all areas of modules 1 and 3 based on objectivity and clarity criteria were adequate. According to Pasquali, ${ }^{45}$ agreement scores were good in both clarity and objectivity criteria. Considering that the ADOS items in modules 1 and 3 (evaluated by judges) are similar to the items in modules 2 and 4 of the instrument, the agreement means obtained indicated excellent preliminary results regarding construct validity. ${ }^{44,45}$

The results of the agreement analysis between the scores assigned by the senior examiner and those given by each specialist were good in the language and communication area (modules 1 and 3 ), and in the reciprocal social interaction and other abnormal behaviors areas (module 3 ). In the areas of stereotyped behaviors and restricted interests and other abnormal behaviors (module 1), coefficients were excellent. ${ }^{47}$ The concordance index between the specialists' and the senior examiner's scores was good. These data showed that the measure of inter-rater reliability approximated the expected or ideal result in relation to an accurate scoring of the items in these modules. The agreement obtained probably reflects the quality of the final version of the instrument.

The agreement percentage for item reciprocal social interaction (module 3 ) was $75 \%$, however with no statistical significance. ${ }^{47} \mathrm{~A}$ possible explanation for this finding is that, of a total of 40 items in this area, 10 were scored "no problem" by the senior examiner, compared to only 1 occurrence in the specialist scoring (only 1 specialist). There were no differences between the specialists' and the senior examiner's scores in the play and stereotyped behaviors and restricted interests areas of module 3 (100\% agreement, as shown in Table 3). However, this result cannot be assessed by kappa coefficients because none of the children received scores on these items, according to both the specialists and the senior examiner. 


\section{Conclusion}

This study describes the steps used in the translation and cultural adaptation of the ADOS scale to Brazilian Portuguese. The ADOS is not commercially available in Brazil, and professionals interested in using it must obtain the appropriate certification from the WPS. Still, this study makes an important contribution, as it gives details of the results of the translation, cultural adaptation, construct validity and semantic equivalence analysis of the instrument, with preliminary data from a pre-test study. The Brazilian Portuguese version of ADOS showed good semantic equivalence, and only a small number of words and phrases were modified in the final version for cultural adaptation purposes. The results of the construct validity analysis were adequate, and agreement means according to clarity and objectivity criteria were excellent in all areas of the two modules. The inter-rater reliability of the ADOS scores between the specialists and the senior examiner was adequate for 7 of 10 areas.

\section{Limitations}

The size sample of this study in the pre-test stage was small. It might be the case that a larger sample size could increase reliability, with better kappa coefficients. Also, there is the lack of the translation and cultural adaptation of the most recent version of the instrument, the ADOS-2, including the module protocol for pre-schoolers. Therefore, a further study should be conducted to develop the translation and cultural adaptation of these items and the modified domains of ADOS-2, in addition to testing its psychometric properties in the Brazilian population. The development of a Brazilian version of ADOS authorized by the WPS has resulted in the creation of a strengthened single national version of the instrument for use in clinical and scientific research into ASD, whilst also deterring the use of other unauthorized versions.

\section{Acknowledgements}

This study received financial support from Coordenação de Aperfeiçoamento de Pessoal de Nível Superior (CAPES), ONG Autismo \& Realidade, and Fundo MACKPESQUISA.

The authors are grateful to Luciana Coltri da Silva, Mayra Muller Spaniol, Noemi Takiuchi and Giovani Amado Rivera who contributed to data collection and data analysis.

\section{Disclosure}

No conflicts of interest declared concerning the publication of this article.

\section{References}

1. American Psychiatric Association. Diagnostic and statistical manual of mental disorders, 5th edition. Washington: APA; 2013.

2. Elsabbagh M, Divan G, Koh Y-J, Kim YS, Kauchali S, Marcín C, et al. Global prevalence of autism and other pervasive developmental disorders. Autism Res. 2012;5:160-79.

3. Fombonne E, Marcin C, Manero AC, Bruno R, Diaz C, Villalobos $M$, et al. Prevalence of autism spectrum disorders in Guanajuato, Mexico: The Leon Survey. J Autism Dev Disord. 2016;46:166985.

4. Paula CS, Cunha GR, Silva LC, Teixeira MCTV. Conceituação do transtorno do espectro autista: definição epidemiológica. In: Bosa CA, Teixeira MCTV, editors. Autismo: avaliação psicológica e neuropsicológica. São Paulo: Hogrefe; 2017. p.7-28.

5. Cawthorpe D. Comprehensive description of comorbidity for autism spectrum disorder in a general population. Perm J. 2017;21:16-088.

6. Brentani H, Paula CS, Bordini D, Rolim D, Sato F, Portolese J, et al. Autism spectrum disorders: an overview on diagnosis and treatment. Braz J Psychiatry. 2013;35:S62-72.

7. Brasil, Ministério da Saúde. Diretrizes de atenção à reabilitação da pessoa com transtorno do espectro do autismo. Brasília: Ministério da Saúde; 2014.

8. Krug DA, Arick J, Almond P. Behavior checklist for identifying severely handicapped individuals with high levels of autistic behavior. J Child Psychol Psychiatry. 1980;21:221-9.

9. Marteleto MRF, Pedromônico MRM. Validity of Autism Behavior Checklist (ABC): preliminary study. Braz J Psychiatry. 2005;27:295-301

10. Rutter M, Bailey A, Lord C. Social Communication Questionnaire. Los Angeles: Western Psychological Services; 2003.

11. Sato FP, Paula CS, Lowenthal R, Nakano EY, Brunoni D, Schwartzman JS, et al. Instrument to screen cases of pervasive developmental disorder: a preliminary indication of validity. Braz J Psychiatry. 2009;31:30-3.

12. Schopler E, Reichler RJ, Renner BR. The childhood autism rating scale (CARS): For diagnostic screening and classification of autism. New York: Irvington; 1986.

13. Pereira A, Riesgo RS, Wagner MB. Autismo infantil: tradução e validação da Childhood Autism Rating Scale para uso no Brasil. J Pediatr (Rio J). 2008;84:487-94.

14. Robins DL, Fein D, Barton ML, Green JA. The Modified Checklist for Autism in Toddlers: an initial study investigating the early detection of autism and pervasive developmental disorders. J Autism Dev Disord. 2001;31:131-44.

15. Losapio MF, Pondé MP. Tradução para o português da escala M-CHAT para rastreamento precoce de autismo. Rev Psiquiatr Rio Gd Sul. 2008;30:221-9.

16. Bosa CA, Zanon RB, Backes B. Autismo: construção de um protocolo de avaliação do comportamento da criança - Protea. Rev Psicol Teor Pratica. 2016;18:194-205.

17. Carvalho FA, Paula CS, Teixeira MCTV, Zaqueu L da CC, Famá D'Antino ME. Rastreamento de sinais precoces de transtornos do espectro do autismo em crianças de creches de um município de São Paulo. Rev Psicol Teor Pratica. 2013;15:144-54.

18. Paula CS, Cunha GR, Bordini D, Brunoni D, Moya AC, Bosa CA, et al. Identifying autism with a brief and low-cost screening instrument OERA: construct validity, invariance testing, and agreement between judges. J Autism Dev Disord. 2018;48:1780-91.

19. Grodberg D, Weinger PM, Kolevzon A, Soorya L, Buxbaum JD. Brief Report: The Autism Mental Status Examination: Development of a brief autism-focused exam. J Autism Dev Disord. 2012;42:4559.

20. Grodberg D, Weinger PM, Halpern D, Parides M, Kolevzon A, Buxbaum JD. The Autism Mental Status Exam: sensitivity and specificity using DSM-5 criteria for autism spectrum disorder in verbally fluent adults. ] Autism Dev Disord. 2014;44:609-14. 
21. Galdino MP, Pegoraro LFL, Saad LO, Grodberg D, Celeri EHRV. Evidence of validity of the Autism Mental Status Examination (AMSE) in a Brazilian Sample. J Autism Dev Disord. 2018;1-6.

22. Lord C, Rutter M, Goode S, Heemsbergen J, Jordan H, Mawhood $L$, et al. Autism Diagnostic Observation Schedule: A standardized observation of communicative and social behavior. J Autism Dev Disord. 1989;19:185-212

23. Lord C, Rutter M, DiLavore PC, Risi S. Autism Diagnostic Observation Schedule (ADOS). Los Angeles: Western Psychological Services; 2000.

24. Lord C, Rutter M, DiLavore PC, Risi S, Gotham K, Bishop S. Autism Diagnostic Observation Schedule, Second Edition (ADOS2). Torrance: Western Psychological Services; 2012.

25. Le Couteur A, Rutter M, Lord C, Rios P, Robertson S, Holdgrafer M, et al. Autism diagnostic interview: A standardized investigatorbased instrument. J Autism Dev Disord. 1989;19:363-87.

26. Lord C, Rutter M, Le Couteur A. Autism Diagnostic InterviewRevised: A revised version of a diagnostic interview for caregivers of individuals with possible pervasive developmental disorders. J Autism Dev Disord. 1994;24:659-85.

27. BölteS, Poustka F. Diagnostische Beobachtungsskala für Autistische Störungen (ADOS): Erste Ergebnisse zur Zuverlässigkeit und Gültigkeit. Z Kinder Jugendpsychiatr Psychother. 2004;32:4550.

28. Li J-H, Zhong J-M, Cai L-Y, Chen Y, Zhou M-Z. Comparison of clinical application of three autism rating scales. Chinese $J$ Contemp Pediatr. 2005; 7:59-62.

29. Gotham K, Pickles A, Lord C. Standardizing ADOS Scores for a measure of severity in autism spectrum disorders. J Autism Dev Disord. 2009;39:693-705.

30. Papanikolaou K, Paliokosta E, Houliaras G, Vgenopoulou S, Giouroukou E, Pehlivanidis A, et al. Using the Autism Diagnostic Interview-Revised and the Autism Diagnostic Observation Schedule-Generic for the diagnosis of autism spectrum disorders in a Greek sample with a wide range of intellectual abilities. J Autism Dev Disord. 2009;39:414-20.

31. Oosterling I, Roos S, Bildt A, Rommelse N, Jonge M, Visser J, et al. Improved diagnostic validity of the ADOS Revised Algorithms: A replication study in an independent sample. J Autism Dev Disord. 2010:40:689-703.

32. Chojnicka I, Ploski R. Polish version of the ADOS (Autism Diagnostic Observation Schedule-Generic). Psychiatr Pol. 2011;46:781-9.

33. Becker MM, Wagner MB, Bosa CA, Schmidt C, Longo D, Papaleo C, et al. Translation and validation of Autism Diagnostic InterviewRevised (ADI-R) for autism diagnosis in Brazil. Arq Neuropsiquiatr. 2012;70:185-90.

34. Falkmer T, Anderson $\mathrm{K}$, Falkmer M, Horlin C. Diagnostic procedures in autism spectrum disorders: a systematic literature review. Eur Child Adolesc Psychiatry. 2013;22:329-40.
35. Sun X, Allison C, Auyeung B, Matthews FE, Zhang Z, Baron-Cohen $S$, et al. Comparison between a Mandarin Chinese version of the Childhood Autism Spectrum Test and the Clancy Autism Behaviour Scale in mainland China. Res Dev Disabil. 2014;35:1599-608.

36. Zander E, Sturm H, Bölte S. The added value of the combined use of the Autism Diagnostic Interview-Revised and the Autism Diagnostic Observation Schedule: Diagnostic validity in a clinical Swedish sample of toddlers and young preschoolers. Autism. 2015; 19:187-99.

37. Chojnicka I, Pisula E. Adaptation and Validation of the ADOS-2, Polish Version. Front Psychol. 2017;8:1916.

38. Rudra A, Banerjee S, Singhal N, Barua M, Mukerji S, Chakrabarti B. Translation and usability of autism screening and diagnostic tools for autism spectrum conditions in India. Autism Res. 2014; 7:598-607.

39. Hus V L Lord C. The Autism Diagnostic Observation Schedule, Module 4: Revised algorithm and standardized severity scores. J Autism Dev Disord. 2014;44:1996-2012.

40. Esler AN, Bal VH, Guthrie W, Wetherby A, Weismer SE, Lord C. The Autism Diagnostic Observation Schedule, Toddler Module: Standardized severity scores. J Autism Dev Disord. 2015;45:270420.

41. Western Psychological Services. Published translations [Internet] [cited Dec 08 2018]. http://www.wpspublish.com/app/ OtherServices/PublishedTranslations.aspx

42. Western Psychological Services. Copyrights permissions [Internet]. [cited Dec 08 2018]. http://www.wpspublish.com/ app/OtherServices/CopyrightsPermissions.aspx

43. International Tests Commission. Directrizes internacionais para a utilização de testes. Lisboa: CEGOC-TEA; 2003. https://www. intestcom.org/files/guideline_test_use_portuguese.pdf.

44. Reichenheim ME, Moraes CL. Operacionalização de adaptação transcultural de instrumentos de aferição usados em epidemiologia. Rev Saude Publica. 2007;41:665-73.

45. Pasquali L. Instrumentação psicológica. Fundamentos e práticas. Porto Alegre: Artmed; 2010.

46. Siegel S, Castellan NJ Jr. Nonparametric statistics for the behavioral sciences international edition. New York: McGraw-Hill; 1988.

47. Pereira MG. Epidemiologia: teoria e prática. Rio de Janeiro: Guanabara Koogan; 2005.

\section{Correspondence:}

Maria Cristina Triguero Veloz Teixeira

Programa de Pós-Graduação em Distúrbios do Desenvolvimento Universidade Presbiteriana Mackenzie

Rua da Consolação, 896, Prédio 28, $1^{\circ}$ andar, Consolação

01302-907 - São Paulo, SP - Brazil

E-mail: cris@teixeira.org 